\title{
Genetic database development for the characterisation of Sicilian sheep population
}

\author{
Viviana Giangreco,Tiziana Lupo, Ignazio Sammarco, Maurizio Bivona, Gabriele Ciaccio, Luca Sineo \& Stefano \\ Reale* $^{*}$
}

Istituto Zooprofilattico Sperimentale della Sicilia “A.Mirri” Via Gino Marinuzzi 3, 90129 Palermo, Italy

"Corresponding author, e-mail: stefano.reale@izssicilia.it

ABSTRACT

KEY WORDS
The most representative sheep in Sicily are Belicina, Comisana, Pinzirita, Barbaresca and the crossbred derived sheep from all this species. In this study, the allelic frequencies of the Sicilian sheep population were investigated. It currently represents the best way to determine the genetic identity and/or family even with limited amounts of sample or when the DNA is degraded. The aim of the study was to provide a reference data bank and to evaluate a microsatellite panel for pedigree analysis as suggested by the International Society for Animal Genetics (ISAG). There are various studies on European sheep, but few datasets were developed on the population of Sicilian sheep. The reference database will include allele frequencies at each locus and will determine genetic parameters for Sicilian ovine species selection. Our results indicated that Hardy Weinberg equilibrium was not always maintained. These results could be explained by a non-random mating. The database is useful to investigate the relationship, the parentage the meat traceability and in disease control programs. The standardized panels of allele frequencies represent a molecular fingerprinting characterizing the subjects with very high definition level and can be useful to control all the livestock. The parentage identification could be important for the veterinary police to investigate the theft or the animal substitutions in the Sicilian farms.

Ovine; microsatellite; locus; allele.

Received 28.11.2019; accepted 19.12.2019; published online 20.12.2019

Proceedings of the 4th International Congress on Biodiversity "Man, Natural Habitats and Euro-Mediterranean Biodiversity", November 17th-19th, 2017 - Malta

\section{INTRODUCTION}

The most representative species of sheep in Sicily are Belicina, Comisana, Pinzirita and Barbaresca. The purpose of this study was to investigate the allelic frequencies in the Sicilian sheep population to provide a reference data bank and to evaluate the use of ISAG (International Society for Animal Genetics) through a microsatellite panel for pedigree analysis. Tandem repeats are used as an ef- fective method to track DNA markers in genotyping field. The deriving database can be useful for the traceability of meat, risk assessment and consumer warranty. The microsatellites are employed as genetic markers for their random distribution, the codominant inheritance (Barbarà et al., 2007), discriminative power and possibility of simultaneous analysis. The microsatellite markers can also be used to trace the meat through the production processes (Vázquez et al., 2004), to study the ge- 
netic diversity of sheep (Peakall \& Smouse, 2012) and to select the animals in breeding programs. Moreover represent the best way to determine the genetic identity and/or family, even with limited amounts of sample or when the DNA is degraded. Commonly the most common approach in ovine breeding systems is the use of multiplesire natural mating based on one or few males. Parentage inaccuracies due to human error getting to wrong animal identification codes can be entered into the herd book (Weller et al., 2004). Significant pedigree record errors seem to be a common problem in sheep that reduces the genetic progress of the populations. Under these scenarios, DNA-based paternity testing provides a powerful tool to carry out precise breeding strategies and improve the overall quality of the flock. DNA Genotyping using marker panels has become the most common procedure for paternity and pedigree testing both in human and livestock species. Many highly polymorphic MST alleles have been studied that are often in the 70$250 \mathrm{bp}$ range. The selection and optimization of a MST panel was successful for parental investigation in randomly chosen animals.

See also other cited bibliography: Barendse et al., 1994; Heyen et al., 1997; Jamieson \& Taylor, 1997; Luikart et al., 1999; Diez-Tascon et al., 2000; Farid et al., 2000; Baron et al., 2002; Visscher et al., 2002; Bruford et al., 2003; Senneke et al., 2004; Van Oosterhout et al., 2004a, b; Baumung et al.,
2006; Jiménez-Gamero et al., 2006; GlowatzkiMullis et al., 2007; Kalinowski et al., 2007; Lawson Handley et al., 2007; Ozkan et al., 2009; ISAG, 2010; Carneiro et al., 2010; Dorji et al., 2010; Saberivand et al., 2010; Azhar et al., 2018.

\section{MATERIAL AND METHODS}

We tested 10 microsatellite markers recommended by ISAG on 452 Sicilian sheep. The microsatellite loci were employed in two homogeneous multiplex group of loci, we use ten ISAG loci for present study: OarFCB011, INRA0063, HSC, OarCP0049, OarFCB0304, CSRD0247, OarFCB020, D5S2, SPS0113, INRA005. Whole blood samples were taken from the Sicilian typical half-breed, species representative of the Sicilian population. Genomic DNA was extracted and purified using a commercial kit (Ezna WVR). Two different PCR test were employed to investigate a panel of ten microsatellites. DNA targets were amplified in a 6-plex and 4-plex PCRs system respectively as follows: $12.5 \mu 1$ Type-it $2 \mathrm{X}$ master mix (Qiagen), $2.5 \mu 1$ Primer mix ( $2 \mu \mathrm{M}$ for each primer), 20 ng DNA. PCRs were carried out using a thermocycler (9700 Applied Biosystems, San Diego, CA, USA). Multiplex-PCR products were analyzed using an ABI PRISM 3130 Genetic Analyzer (Applied Biosystems). Genotypic profiles

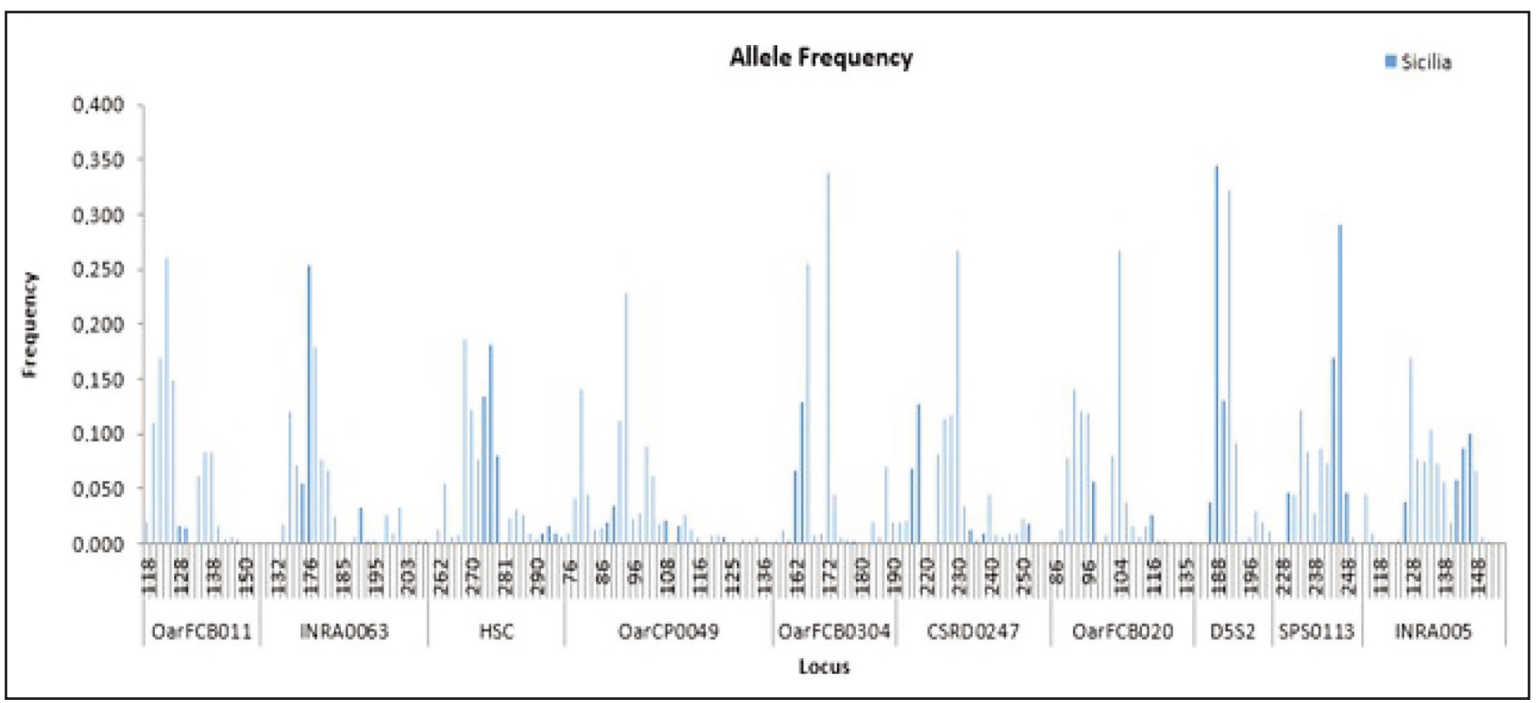

Figure 1. Allele frequency observed at each locus for every examined samples. (GenAlEx v6.5 software). 


\begin{tabular}{|c|c|c|c|c|c|c|c|c|c|c|c|}
\hline Locus & $\mathbf{N}$ & NA & NE & NE/NA & MAF & HO & HE & Fis & PIC & PE & PI \\
\hline OarFCB011 & 452 & 22 & 8.42 & 0.383 & 0.187 & 0.771 & 0.881 & 0.007 & 0.853 & 0.80 & 0.033 \\
\hline INRA0063 & 452 & 31 & 13.40 & 0.433 & 0.138 & 0.772 & 0.925 & 0.090 & 0.914 & 0.85 & 0.023 \\
\hline HSC & 452 & 20 & 9.75 & 0.488 & 0.188 & 0.783 & 0.897 & 0.024 & 0.876 & 0.81 & 0.022 \\
\hline OarCP0049 & 452 & 36 & 12.51 & 0.347 & 0.161 & 0.763 & 0.922 & 0.091 & 0.907 & 0.89 & 0.014 \\
\hline OarFCB0304 & 452 & 28 & 5.54 & 0.191 & 0.345 & 0.651 & 0.819 & 0.024 & 0.754 & 0.83 & 0.063 \\
\hline CSRD0247 & 452 & 37 & 9.68 & 0.262 & 0.197 & 0.804 & 0.897 & 0.001 & 0.875 & 0.87 & 0.024 \\
\hline OarFCB020 & 452 & 24 & 8.79 & 0.366 & 0.187 & 0.758 & 0.886 & 0.030 & 0.860 & 0.82 & 0.028 \\
\hline D5S2 & 452 & 13 & 4.14 & 0.319 & 0.329 & 0.614 & 0.759 & -0.050 & 0.642 & 0.68 & 0.095 \\
\hline SPS0113 & 452 & 18 & 7.11 & 0.395 & 0.235 & 0.642 & 0.859 & 0.112 & 0.820 & 0.77 & 0.034 \\
\hline INRA005 & 452 & 30 & 12.22 & 0.407 & 0.130 & 0.681 & 0.918 & 0.176 & 0.905 & 0.82 & 0.013 \\
\hline Mean & & 25.9 & 9.157 & 0.359 & 0.209 & 0.723 & 0.876 & 0.051 & 0.841 & 0.81 & 0.034 \\
\hline
\end{tabular}

Table 2. Genetic parameters in Sicilian sheep population. NA = number of alleles; NE = number of effective alleles; MAF = minor allele frequency; $\mathrm{HO}=$ observed heterozygosity; $\mathrm{HE}=$ expected heterozygosity; Fis = inbreeding coefficient; PIC = polymorphic information content; $\mathrm{PE}=$ probability of exclusion; $\mathrm{PI}=$ probability of identity.

were read and analyzed by GeneMapper software v4.0 (Applied Biosystems). Statistical analysis of data generated from the 10 markers that were analyzed was performed using GenAlEx (Peakall \& Smouse, 2012), PowerMarker (Liu \& Muse, 2005), and Micro-Checker (Van Oosterhout et al., 2004) softwares. All these are a useful set of bioinformatic tools specific for genetic populations analysis im- plementing various data management algorithms. The number of effective alleles $\left(\mathrm{N}_{\mathrm{E}}\right)$, allele number $\left(\mathrm{N}_{\mathrm{A}}\right)$, allele frequency, observed and expected heterozygosities $\left(\mathrm{H}_{\mathrm{O}}\right.$ and $\mathrm{H}_{\mathrm{E}}$, respectively), probability of Identity $\left(\mathrm{P}_{\mathrm{ID}}\right)$, defined as the probability that two individuals drawn at random from a population will have the same genotype at multiple loci, probability of exclusion of a locus $\left(\mathrm{P}_{\mathrm{E}}\right)$, and the devia- 
tion probability from the Hardy-Weinberg equilibrium (HWE) were obtained using the GenAlEx v6.5 software. The expected homozygosity (HomE), observed homozygosity (HomO), homozygosity excess, evidence for null allele, evidence for large allele dropout, and evidence for scoring error due to stuttering were obtained using the MicroChecker v2.2 software. The polymorphism information content (PIC), inbreeding coefficient, genotype number (NG), major allele frequency (MAF), and major genotype frequency (MGF) were investigated using the PowerMarker v3.25 software.

\section{RESULTS}

In total, 452 related and unrelated sheep were genotyped, the average observed heterozygosity was lower than the expected value (0.701 vs 0.852$)$. The exact test for Hardy-Weinberg proportion, allele number and inbreeding coefficient were calculated. These results could be explained by a nonrandom mating studies on a larger number of samples. The polymorphic information content (PIC) calculated according Botstein et al. (1980) ranged from 0.642 for locus $\mathrm{D} 5 \mathrm{~S} 2$ to 0.914 for locus INRA0063. PIC is a parameter that indicates the degree of marker informativeness describing genotypic variation in single base pair or in larger sequence repeats. The PIC value will be almost zero if there is no allelic variation. All locus were informative (PIC > 0.5) (Table 1), with a mean PIC of 0.841 . The heterozygosity expected $\mathrm{H}_{\mathrm{E}}$ and observed $\mathrm{H}_{\mathrm{O}}$, as measures of genetic diversity at a single locus, are shown in Table 1 . In all cases, $\mathrm{H}_{\mathrm{O}}$ was lower than $\mathrm{H}_{\mathrm{E}}$.

\section{DISCUSSION AND CONCLUSIONS}

To establish a livestock conservation program it is fundamental the genetic characterization of the entire population under study. For different breeds must have taken into account also phenotypic differences (morphology, milk production, disease resistance etc) and information about provenience of samples. A database of frequencies for the different alleles of known microsatellite markers it's important to help researcher in studying the phylogeny of one or more populations, to discover patterns of relationships among different groups or associate the genetic markers with important productive characteristics. Analysis of different samples of sheep resulted in a set of genotype profiles of the most representative ovine populations from Sicily. The principal statistics parameter of sheep population were obtained elaborating microsatellites alleles frequencies through a set of statistical analysis tools in particular Genalex and PowerMarker software and Micro-Checker. The final data show a significant deficiency in the $\mathrm{H}_{\mathrm{O}}$ value compared to the $\mathrm{H}_{\mathrm{E}}$ value. This deviation from HWE can be caused by inbreeding, assortative mating or Wahlund effect, due to a fragmentation of the original population into subpopulations. But loss of heterozygosity can also include genotyping errors due to nonamplified alleles (null alleles) caused by mutations in primer binding site (Pemberton et al., 1995), short allele dominance (large allele dropout) and the scoring of stutter peaks dropout. Finally, we observed an homozygote excess in all loci compared to the expected value. Five loci (OarFCB0304, CSRD0247, D5S2, SPS0113, INRA005) showed a strong evidence for scoring error due to stuttering, and none of these loci had large allele dropout. It is not clear whether the homozygote excess is due to null alleles or if it really reflects the genotypes of the Sicilian sheep population.

\section{REFERENCES}

Azhar P.M., Chakraborty D., Iqbal Z., Malik A.A., Ajaz qaudir, Asfar A., Bhat I.A., 2018. Microsatellite Markers as a Tool for Characterization of Small Ruminants: A Review. International Journal of Current Microbiology and Applied Sciences, 7: 1330-1342. 10.20546/ijcmas.2018.701.162

Barbará T., Palma-Silva C., Paggi G.M., Bered F., Fay M.F. \& Lexer C., 2007. Cross-species transfer of nuclear microsatellite markers: potential and limitations. Molecular Ecology, 16: 3759-3767. https://doi. org/10.1111/j.1365-294X.2007.03439.x

Baron E.E., Martinez M.L., Verneque R.S. \& Coutinho L.L., 2002. Parentage testing and effect of misidentification on the estimation of breeding value in Gir cattle. Genetics and Molecular Biology, 25: 389394. https://doi.org/10.1590/S1415-4757200200040 0006

Barendse W., Armitage S.M., Kossarek L.M., Shalom A., Kirkpatrick B.W., Ryan A.M., Clayton D., Li L., 
Neibergs H.L., Zhang N., Grosse W.M., Weiss J., Creighton P., McCarthy F., Ron M., Teale A.J., Fries R., McGraw R.A., Moore S.S., Georges M., Soller M., Womack J.E. \& Hetzel D.J.S., 1994. A genetic linkage map of the bovine genome. Nature Genetics, 6: 227-235.

Botstein D., White R.L., Skalnick M.H. \& Davies R.W., 1980. Construction of a genetic linkage map in man using restriction fragment length polymorphism. American Journal of Human Genetics, 32: 314-331.

Bruford M.W., Bradley D.G. \& Luikart G., 2003. DNA markers reveal the complexity of livestock domestication. Nature Reviews Genetics, 4: 900-910. https:// doi.org/10.1038/nrg1203

Baumung R., Cubric-Curik V., Schwend K., Achmann R. \& Sölkner J., 2006. Genetic characterisation and breed assignment in Austrian sheep breeds using microsatellite marker information. Journal of Animal Breeding and Genetics, 123: 265-271. https://doi. org/10.1111/j.1439-0388.2006.00583.x

Carneiro H., Louvandini H., Paiva S.R., Macedo F., Mernies B. \& Mcmanus C., 2010. Morphological characterization of sheep breeds in Brazil, Uruguay and Colombia. Small Ruminant Research, 94: 58-65. https://doi.org/10.1016/j.smallrumres.2010.07.001

Diez-Tascon C., Littlejohn R.P., Almeida P.A. \& Crawford A.M., 2000. Genetic variation within the Merino sheep breed: analysis of closely related populations using microsatellites. Animal Genetics, 31: 243-251. https://doi.org/10.1046/j.1365-2052.2000. 00636.x

Dorji T., Jianlin H., Wafula P., Yamamoto Y., Sasazaki S., Oyama K., Hanotte O., Lin B.Z. \& Mannen H., 2010. Sheep genetic diversity in Bhutan using microsatellite markers. Animal Science Journal, 81: 145-151. https://doi.org/10.1111/j.1740-0929.2009. 00723.x

Farid A., O’Reilly E., Dollard C. \& Kelsey C.R. Jr., 2000. Genetic analysis of ten sheep breeds using microsatellite markers. Canadian Journal of Animal Science, 80: 9-17.

Glowatzki-Mullis M.L., Muntwyler J. \& Gaillard C., 2007. Cost-effective parentage verification with $17-$ plex PCR for goats and 19-plex PCR for sheep. Animal Genetics, 38: 86-88. https://doi.org/10.1111/j. 1365-2052.2006. 01550.x

ISAG, 2010. Applied Genetics in Sheep and Goats Workshop. In: 32th International Conference on Animal Genetics. Available at [www.isag.us/Docs/Applied_GeneticsSheepGoats_CT.pdf].

Jamieson A. \& Taylor S.C.S., 1997. Comparison of three probability formulae for parentage exclusion. Animal Genetics, 28: 397-400.

Jiménez-Gamero I., Dorado G., Muñoz-Serrano A., Analla M. \& Alonso-Moraga A., 2006. DNA microsatellites to ascertain pedigree recorded information in a select- ing nucleus of Murciano-Granadina dairy goats. Small Ruminant Research, 65: 266-273. https://doi.org/10. 1016/j.smallrumres.2005.07.019

Kalinowski S.T., Taper M.L. \& Marshall T.C., 2007. Revising how the computer program CERVUS accommodates genotyping error increases success in paternity assignment. Molecular Ecology, 16: 10991106. https://doi.org/10.1111/j.1365-294X.2007.03 089.x

Lawson Handley L.J., Byrne K., Santucci F., Townsend S., Taylor M., Bruford M.W. \& Hewitt G.M., 2007. Genetic structure of European sheep breeds. Heredity, 99: 620-631. https://doi. org/10.1038/sj.hdy.680 1039

Liu K. \& Muse S.V., 2005. PowerMarker: an integrated analysis environment for genetic marker analysis. Bioinformatics, 21 :2128-2129. https://doi. org/10.1093/bioinformatics/ bti282

Luikart G., Biju-Duval M.P., Ertugrul O., Zagdsuren Y., Maudet C. \& Taberlet P., 1999. Power of $22 \mathrm{mi}-$ crosatellite markers in fluorescent multiplexes for parentage testing in goats (Capra hircus). Animal Genetics, 30: 431-438. https://doi.org/10.1046/j.13652052.1999.00545.x

Heyen D.W., Beever J.E., Da Y., Evert R.E., Green C., Bates S.R., Ziegle J.S. \& Lewin H.A.,1997. Exclusion probabilities of 22 bovine microsatellite markers in fluorescent multiplexes for semi-automated parentage testing. Animal Genetics, 28: 21-27. https://doi. org/10.1111/j.1365-2052.1997.t01-1-00057.x

Ozkan E., Soysal M.I., Ozder M., Koban E., Sahin O. \& Togan I., 2009. Evaluation of parentage testing in the Turkish Holstein population based on 12 microsatellite loci. Livestock Science, 124, 101-106. https:// doi.org/10.1016/j.livsci.2009.01.004

Peakall R. \& Smouse P.E., 2012. GenAlEx 6.5: genetic analysis in Excel. Population genetic software for teaching and research-an update. Bioinformatics, 28: 2537-2539. https://doi.org/10.1093/bioinformatics/ bts 460

Pemberton J.M., Slate J., Bancroft D.R. \& Barrett J.A., 1995. Non amplifying alleles at microsatellite loci: a caution for parentage and population studies. Molecular Ecology, 4: 249-252. https://doi.org/10.1111/j. 1365-294x.1995.tb00214.x

Saberivand A., Mohammadi G. \& Javanmard A., 2010. Genetic variation of ten microsatellite loci in Makui sheep of Iran. Veterinary Research Communications, 34: 541-548. https://doi.org/10.1007/s11259-0109428-8

Senneke S.L., MacNeil M.D. \& Van Vleck L.D., 2004. Effects of sire misidentification on estimates of genetic parameters for birth and weaning weights in Hereford cattle. Journal of Animal Science, 82: 2307-2312. 
Visscher P.M., Woolliams J.A., Smith D. \& Williams J.L., 2002. Estimation of pedigree errors in the UK dairy population using microsatellite markers and the impact on selection. Journal of Dairy Science, 85: 2368-2375. https://doi.org/10.3168/jds.S0022-0302 (02)74317-8

Van Oosterhout C., Weetman D., Hutchinson W.F., 2004a. Estimation and adjustment of microsatellite null alleles in nonequilibrium populations. Molecular Ecology Notes, 6: 255-256. https://doi.org/10.1111/j. 1471-8286.2005.01082.x

Van Oosterhout C., Hutchinson W.F., Wills D.P.M. \& Shiplet P., 2004b. Micro-checker: software for iden- tifying and correcting genotyping errors in microsatellite data. Molecular Ecology Notes, 4: 535-538. https://doi.org/10.1111/j.1471-8286.2004.00 684.x Vázquez J.F., Péres T., Ureña F, Gudín E., Albornoz J. \& Domínguez A., 2004. Practical Application of DNA Fingerprinting To Trace Beef. Journal of Food Protection, 67: 972-979. https://doi.org/110.4315/ 0362028X-67.5.972

Weller J.I., Feldmesser E., Golik M. \& Tager-Cohen I., 2004. Factors Affecting Incorrect Paternity Assignment in the Israeli Holstein Population. Journal of Dairy Science, 87: 2627-2640. https://doi.org/10. 3168/ jds.S0022-0302(04)73389-5 